\title{
Microstructure of a Spinodal Fe-Ni-Mn-Al Alloy
}

I. Baker*, J. A. Hanna*, M. W. Wittmann*, P. R. Munroe**

*Thayer School of Engineering, Dartmouth College, 8000 Cummings Hall, Hanover, NH 03755

**Electron Microscope Unit, University of New South Wales, Sydney, NSW2052, Australia

The crystal structures, chemical compositions, and morphology of the phases in a new quaternary alloy, $\mathrm{Fe}_{30} \mathrm{Ni}_{20} \mathrm{Mn}_{25} \mathrm{Al}_{25}$, were investigated using transmission electron microscopy (TEM), electron and x-ray diffraction, and x-ray energy dispersive spectroscopy (EDS). This alloy is of interest for its very high strength and hardness, and as an example of a class of quaternary transition metal alloys in which both spinodal decomposition behavior and ordering reactions are found. The alloy is also somewhat magnetic.

TEM of an arc-cast $\mathrm{Fe}_{30} \mathrm{Ni}_{20} \mathrm{Mn}_{25} \mathrm{Al}_{25}$ ingot revealed a periodic microstructure consisting of alternating $\sim 45 \mathrm{~nm}$ and $\sim 55 \mathrm{~nm}$ wide rods with coherent $\{100\}$ interfaces, see Figure 1 . Convergent beam electron diffraction showed that the crystal structures of these phases were b.c.c. and B2, respectively. The lattice parameters of the two phases were indistinguishable by $\mathrm{x}$-ray diffraction, with both in the range $2.913 \pm 0.007 \AA$. However, EDS analysis showed that the compositions of the two phases differed markedly, with much of the Al and nearly all the Ni segregated into the B2 phase, while most of the Fe and Mn were in the b.c.c. phase, see Table 1.

TEM of $\mathrm{Fe}_{30} \mathrm{Ni}_{20} \mathrm{Mn}_{25} \mathrm{Al}_{25}$ samples annealed at $550^{\circ} \mathrm{C}$ for $16 \mathrm{~h}$ revealed the presence of incoherent third-phase precipitates; these had grown to micron-scale after annealing for $115 \mathrm{~h}$ at the same temperature, see Figure 2. The composition of these precipitates is rich in $\mathrm{Fe}$ and $\mathrm{Mn}$, see Table 1, and diffraction patterns from them indicate a $\beta-\mathrm{Mn}$ structure.

The initial, metastable microstructure is strongly suggestive of formation by a spinodal decomposition mechanism. Observation of electron diffraction patterns in a hot straining stage, and analysis of samples quenched from high temperatures, indicated that the parent phase was B2-ordered.

\section{ACKNOWLEDGMENTS}

This research was supported by NIST grant 60NANB2D0120 and NSF grant DMR0314209. The views and conclusions contained herein are those of the authors and should not be interpreted as necessarily representing official policies, either expressed or implied, of the National Science Foundation, the National Institute of Standards and Technologies, or the U.S. Government. 

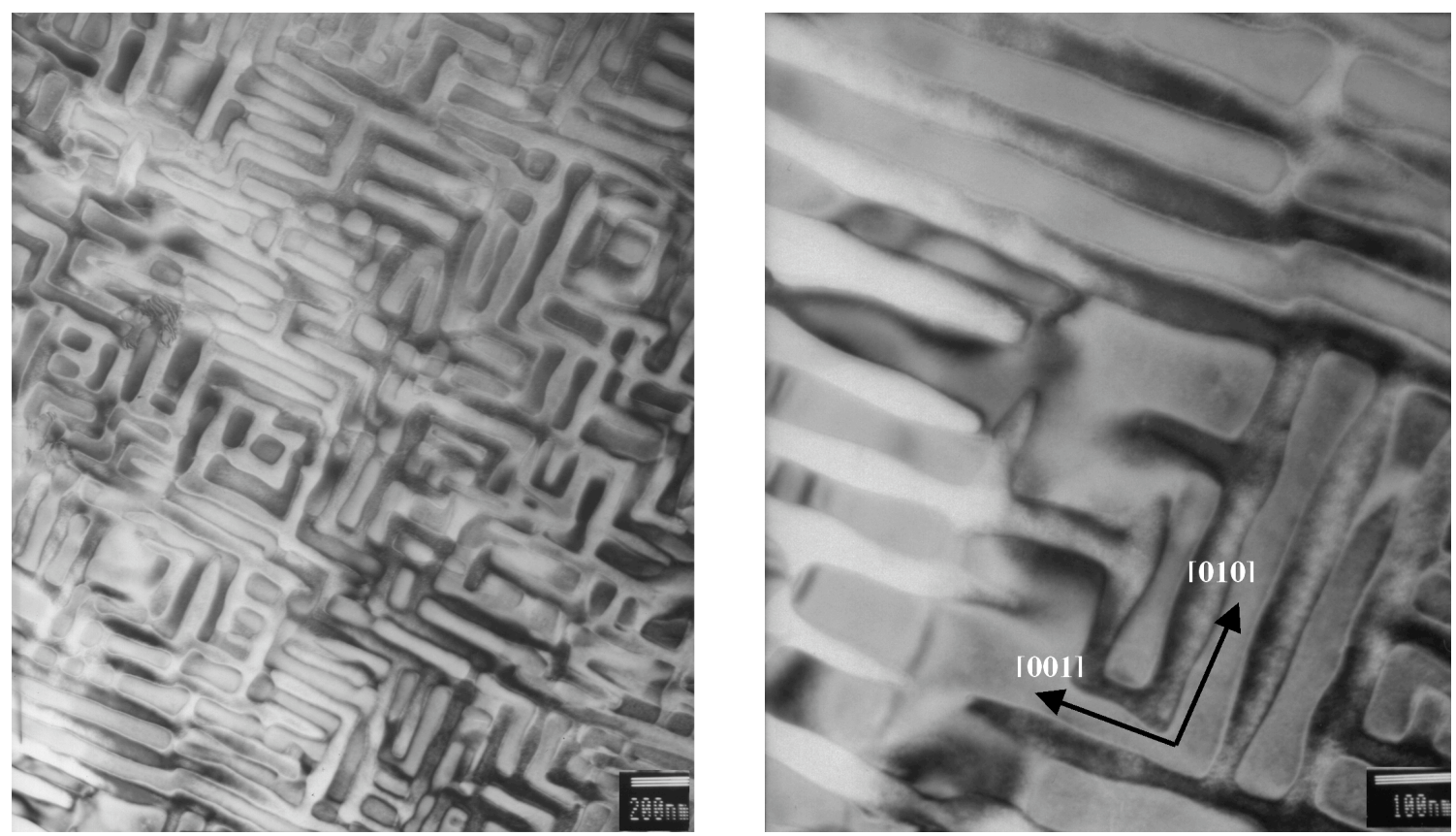

Figure 1: Bright-field images of as-cast $\mathrm{Fe}_{30} \mathrm{Ni}_{20} \mathrm{Mn}_{25} \mathrm{Al}_{25}$ viewed along [100].

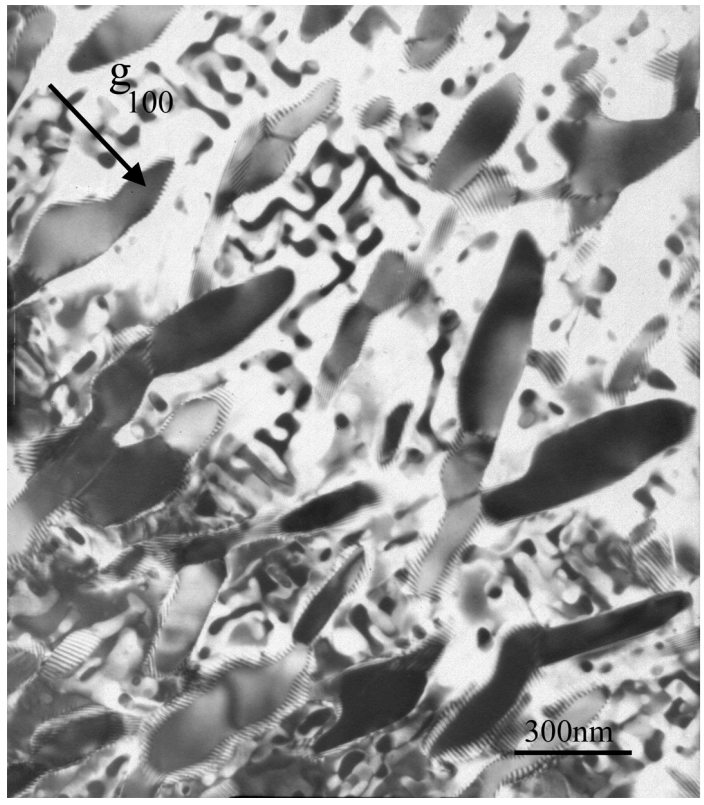

Figure 2: Dark field image of

$\mathrm{Fe}_{30} \mathrm{Ni}_{20} \mathrm{Mn}_{25} \mathrm{Al}_{25}$ after $115 \mathrm{~h}$ at $550^{\circ} \mathrm{C}$, taken along $<100>$ using a $\{010\}$ superlattice reflection, showing remnants of the spinodal microstructure between coarsened third-phase " $\beta-\mathrm{Mn}$ ” particles.

Table 1: Chemical composition (at.\%) of phases in $\mathrm{Fe}_{30} \mathrm{Ni}_{20} \mathrm{Mn}_{25} \mathrm{Al}_{25}$, as determined by EDS.

\begin{tabular}{|l|c|l|l|l|}
\hline \multicolumn{1}{|c|}{ Phase } & \multicolumn{1}{c|}{ Fe } & \multicolumn{1}{c|}{ Ni } & \multicolumn{1}{c|}{ Mn } & \multicolumn{1}{c|}{ Al } \\
\hline BCC (as-cast) & $49.1 \pm 1.0$ & $1.6 \pm 0.15$ & $30.0 \pm 1.0$ & $19.3 \pm 1.4$ \\
\hline B2 (as-cast) & $12.7 \pm 0.5$ & $34.3 \pm 0.8$ & $13.9 \pm 0.5$ & $38.9 \pm 0.9$ \\
\hline Third phase $\left(115 \mathrm{~h}\right.$ at $\left.550^{\circ} \mathrm{C}\right)$ & $45.4 \pm 0.9$ & $<1$ & $42 \pm 1.2$ & $12.3 \pm 0.2$ \\
\hline
\end{tabular}

